\title{
Deletion of angiotensin II type 2 receptor accelerates adipogenesis in murine mesenchymal stem cells via Wnt10b/beta-catenin signaling
}

\author{
Kenichi Matsushita ${ }^{1,2}$, Yaojiong Wu1 ${ }^{1}$, Richard E Pratt ${ }^{1}$ and Victor J Dzau ${ }^{1,3}$
}

Recent evidence suggests that the renin-angiotensin system (RAS) has a vital role in adipocyte biology and the pathophysiology of metabolic syndrome. Obesity is the main culprit of metabolic syndrome; and mesenchymal stem cells (MSCs) have been forwarded as a major source of adipocyte generation. Previously, we reported that MSCs have a local RAS and that pharmacological blockade of angiotensin II type 2 receptor $\left(A T_{2} R\right)$ promotes adipogenesis in human MSCs. However, the definitive roles of $A T_{2} R$ and how $A T_{2} R$ functions in adipogenesis remains unknown. To this end, we employed $A T_{2} R$-null murine MSCs to characterize how $A T_{2} R$ affects the differentiation of MSCs into adipocytes. Murine MSCs were isolated from $\mathrm{AT}_{2} \mathrm{R}$-null mice and wild-type littermates, grown to confluency, and then differentiated into adipocytes. Adipogenesis was quantitated by assessing the lipid droplet accumulation. Using the lipophilic fluorescent dye, the $\mathrm{AT}_{2} \mathrm{R}$-null cells showed significantly increased total fluorescence $(261.6 \pm 49.6 \%$ vs littermate) on day 7 . Oil red $\mathrm{O}$ staining followed by extraction of the absorbed dye and measurement of the absorbance on day 14 also exhibited significantly increased lipid droplet accumulation in the $\mathrm{AT}_{2} \mathrm{R}$-null cells (202.7 $\pm 14.1 \%$ vs littermate). We also examined the expression of adipogenic marker genes by quantitative RT-PCR. The $\mathrm{AT}_{2} \mathrm{R}$-null group exhibited significantly increased expression of PPAR-gamma, fatty acid synthase, and adiponectin (vs littermate). We further examined the role of Wnt $10 \mathrm{~b} /$ beta-catenin signaling, which reportedly has an important inhibitory role in adipogenesis. The $\mathrm{AT}_{2} \mathrm{R}$-null group exhibited significantly decreased Wnt10b expression accompanied by decreased beta-catenin (vs littermate). Our results thus revealed that the $A T_{2} R$ inhibits adipogenic differentiation in murine MSCs. Moreover, this inhibitory effect is associated with Wnt10b/beta-catenin signaling. These results provide important insights into the pathophysiology of obesity and obesity-related consequences such as metabolic syndrome, hinting at possible future therapies.

Laboratory Investigation (2016) 96, 909-917; doi:10.1038/labinvest.2016.66; published online 13 June 2016

Metabolic syndrome is associated with an increased risk of cardiovascular disease. ${ }^{1-3}$ Obesity is a major risk factor of metabolic syndrome and is associated with a combined increase in fat cell size and fat cell number. ${ }^{4-6}$ Irrespective of age, new fat cells arise from a pre-existing pool of adipose stem cells, ${ }^{7-9}$ which are similar to bone marrow-derived mesenchymal stem cells (MSCs). ${ }^{9-11}$ In addition, Liechty et al. ${ }^{12}$ demonstrated that human MSCs transplanted into fetal sheep marrow successfully differentiated and incorporated into normal adult adipose tissue. Developmentally, MSCs equate to the step between undifferentiated mutipotent embryonic stem cells and adipose tissue-derived preadipocytes, and MSCs are a major cell source for adipogenesis. ${ }^{13-15}$
MSCs are suggested to have an important role in maintaining the mass and function of adult adipose tissue. Accordingly, in vitro differentiation of MSCs toward the adipogenic lineage provides a useful means for studying the earliest regulation of adipose cell development.

The renin-angiotensin system (RAS) is one of the most important regulators of cardiovascular homeostasis. ${ }^{16-18}$ Clinical and experimental evidence suggest that RAS also has a role in metabolic syndrome, a cluster of conditions increasing the risk of cardiovascular disease. ${ }^{19-21}$ Importantly, it was reported that the adipocyte contains a complete RAS and that angiotensin influences preadipocyte maturation and differentiation, although the studies presenting such evidence

\footnotetext{
${ }^{1}$ Division of Cardiology, Department of Medicine, Duke University Medical Center, Durham, NC, USA; ${ }^{2}$ Division of Cardiology, Second Department of Internal Medicine, Kyorin University School of Medicine, Tokyo, Japan and ${ }^{3}$ National Academy of Medicine, Washington, DC, USA

Correspondence: Professor VJ Dzau, MD, Division of Cardiology, Department of Medicine, Duke University Medical Center, GSRB II, Room 4035, 210 Research Drive, Durham, NC 27710, USA.

E-mail: VDzau@nas.edu

Received 1 March 2016; revised 15 April 2016; accepted 3 May 2016
} 
are limited and conflicting. ${ }^{22-26}$ Regarding the relationship between RAS and MSC adipogenesis, we previously reported that human MSCs express all the RAS components and produce endogenous (local) angiotensin II, and that pharmacological blockade of angiotensin II (Ang II) type 2 receptor $\left(\mathrm{AT}_{2} \mathrm{R}\right)$ by PD123319 promotes adipogenesis in human MSC. ${ }^{27}$ Many pro-adipogenic stimuli or molecules have been reported to inhibit the osteogenesis of MSCs. ${ }^{28-30}$ Recently, we further reported that pharmacological blockade of $\mathrm{AT}_{2} \mathrm{R}$ inhibits osteogenesis in human MSC. ${ }^{31}$ Together, these results suggest that $\mathrm{AT}_{2} \mathrm{R}$ has anti-adipogenic and pro-osteogenic effects on MSCs. However, the pharmacological blockade of $\mathrm{AT}_{2} \mathrm{R}$ in turn stimulates Ang II type 1 receptor. Thus, definitive examination of the $\mathrm{AT}_{2} \mathrm{R}$ roles in adipogenesis requires studies conducted on $\mathrm{AT}_{2} \mathrm{R}$-null MSCs. Accordingly, we used $\mathrm{AT}_{2} \mathrm{R}$-null murine MSCs to characterize how $\mathrm{AT}_{2} \mathrm{R}$ affects the differentiation of murine MSCs into adipocytes in this study.

Wnt/beta-catenin signaling is a major regulator of MSC fate. ${ }^{32,33}$ In particular, Wnt10b was reported to be the most important endogenous regulator of adipogenesis, ${ }^{34}$ and transgenic mice overexpressing Wnt10b from the adipocytespecific FABP4 promotor show reduced adiposity. ${ }^{35}$ It was also reported that expression of Wnt10b in adipose tissue reduced adiposity in the $o b / o b$ obesity murine model. ${ }^{36}$ Thus, Wnt10b/beta-catenin signaling is considered to act as a brake for adipogenic differentiation.

In the present study, we test our hypothesis that $\mathrm{AT}_{2} \mathrm{R}$ has an important role in adipogenic differentiation of MSCs using a genetic model. Our data demonstrate that the deletion of $\mathrm{AT}_{2} \mathrm{R}$ accelerates adipogenesis in murine MSCs. Furthermore, this inhibitory effect of $\mathrm{AT}_{2} \mathrm{R}$ on adipogenesis is associated with Wnt10b/beta-catenin signaling.

\section{MATERIALS AND METHODS}

\section{Murine Mesenchymal Stem Cell Isolation and Culture}

All animal procedures were approved by the Duke University Institutional Animal Care and Use Committees. Eight-weekold male $\mathrm{AT}_{2} \mathrm{R}$-null (AT2RKO) mice and wild-type male littermates were used in the present study. Because the $\mathrm{AT}_{2} \mathrm{R}$ gene is located on the $\mathrm{X}$ chromosome, heterozygous females were mated with wild-type males to obtain hemizygous males. Animals were genotyped as previously described, ${ }^{37-39}$ and the murine MSCs were isolated by their adherence to plastic as previously described. ${ }^{40-47}$ Bone marrow was collected from 8-week-old male AT2RKO mice and wild-type male littermates by flushing femurs and tibias with the murine MSC growth medium, which comprised Minimum Essential Medium alpha (MEM alpha) with GlutaMAX (Invitrogen, Carlsbad, CA, USA), 20\% fetal bovine serum (FBS), and penicillin/streptomycin $(100 \mathrm{U} / \mathrm{ml}$ and $100 \mu \mathrm{g} / \mathrm{ml}$, respectively). The bone marrow cells were then filtered through a $40-\mu \mathrm{m}$ nylon mesh filter. Mononuclear cells were separated by gradient-density centrifugation using Ficoll-Paque Plus (Amersham Bioscience, Uppsala, Sweden). Cells were then washed twice with phosphate-buffered saline and plated in plastic dishes. After 3 days, non-adherent cells were removed by two washes with phosphate-buffered saline, and adherent cells were further cultured in the murine MSC growth medium. Cells were then propagated in culture. Medium was changed every 3 days.

Confluent cells were incubated in adipogenic medium (Alpha-MEM-GlutaMax medium supplemented with $10 \mu \mathrm{g} / \mathrm{ml}$ insulin, $0.1 \mu \mathrm{mol} / 1$ dexamethasone, $50 \mu \mathrm{mol} / 1$ 3-isobutyl-1methyl-xanthine, $20 \mu \mathrm{mol} / \mathrm{l}$ indomethacin, $20 \%$ FBS, $100 \mathrm{U} / \mathrm{ml}$ penicillin, and $100 \mu \mathrm{g} / \mathrm{ml}$ streptomycin) for 7-14 days. Medium was changed every 3 days.

\section{Quantification of Lipid Droplet Accumulation by AdipoRed Assay}

To quantitate adipocyte differentiation on day 7, AdipoRed Assay Reagent (Cambrex, Walkersville, MD, USA) was employed following the manufacturer's protocol. AdipoRed is a fluorescent dye that binds to lipid droplets. Total fluorescent signal was quantitated using a fluorimeter with an excitation wavelength of $485 \mathrm{~nm}$ and an emission wavelength of $590 \mathrm{~nm}$.

\section{Oil Red O Staining}

For Oil Red $\mathrm{O}$ staining and quantification of adipogenesis on day 14, the Adipogenesis Assay Kit (Chemicon International, Temecula, CA, USA) was used following the manufacturer's protocol. Day-14 cells were washed with phosphate-buffered saline twice and then stained with $0.36 \%$ Oil Red O solution (Adipogenesis Assay Kit) for $15 \mathrm{~min}$ at room temperature. The staining solution was then removed and the cells were washed three times with wash solution (Adipogenesis Assay Kit). The Dye Extraction Solution (Adipogenesis Assay Kit) was then added, and the plates were set on an orbital shaker for $15 \mathrm{~min}$. The absorbance of the extracted dye was measured at $520 \mathrm{~nm}$.

\section{Quantitative Reverse Transcription-PCR}

Total RNA was isolated using Tri Reagent (Sigma, St Louis, MO, USA), further purified on RNeasy columns (Qiagen, Valencia, CA, USA), and quantified by concentration using spectrophotometry. First-strand cDNA was synthesized from the total RNA using a High Capacity cDNA Archive Kit (Applied Biosystem, Foster City, CA, USA) following the manufacturer's protocol. The taqman probe primer system (Applied Biosystem) was used for quantitative reverse transcription-PCR (RT-PCR). The primer and probe sets for murine peroxisome proliferator-activated receptor-gamma (PPARgamma), fatty acid synthase (FAS), adiponectin, Wnt10b, and the housekeeping gene glyceraldehyde-3-phosphate dehydrogenase (GAPDH) were purchased from Applied Biosystems. TaqMan PCR was performed using the ABI Prism 7700 Sequence Detection System, according to the manufacturer's instructions (Applied Biosystems). Target-gene mRNA expression was normalized to GAPDH mRNA expression, and the 
relative amounts of all mRNAs were calculated using the comparative CT method. ${ }^{48}$

\section{Immunoblotting}

Cells on day 14 were lysed at $4{ }^{\circ} \mathrm{C}$ with RIPA Lysis Buffer (Upstate, Lake Placid, NY, USA). Equal amounts of proteins (20 $\mu$ g per lane) were separated by NuPAGE $4-12 \%$ Bis-Tris Gel electrophoresis (Invitrogen). Protein fractions were then electrophoretically transferred onto polyvinylidene difluoride membrane. The membrane was blocked with Blocker/Diluent solution (Western Blot Kit, Invitrogen), and then incubated with rabbit polyclonal antibody to human beta-catenin (Cell Signaling Technology, Danvers, MA, USA) for $1 \mathrm{~h}$ at room temperature. After washing in wash buffer (Western Blot Kit, Invitrogen), the membrane was incubated with horseradish peroxidase-conjugated anti-rabbit immunoglobulin G (Western Blot Kit, Invitrogen) for $1 \mathrm{~h}$ at room temperature. The antigen antibody-peroxidase complex was visualized using the ECL chemiluminescence solution (Western Blot Kit, Invitrogen). The blot was subsequently stripped using the Re-Blot Plus Western Blot Recycling Kit (Chemicon International) and rehybridized with an anti-GAPDH antibody (Santa Cruz Biotechnology, Santa Cruz, CA, USA) as a control for protein loading. Then, the blot was restripped and rehybridized with rabbit polyclonal antibody to PPAR-gamma (Abcam, Cambridge, MA, USA). Densitometric quantitation was performed using ImageJ software (NIH, Bethesda, MD, USA), and the band intensities of beta-catenin and PPARgamma were standardized to those of GAPDH.

\section{Statistical Analysis}

All statistical procedures were performed using the Statgraphics Plus version 5.0 software (StatPoint, Herndon, VA, USA). Comparisons between groups were made using Student's $t$ test, and the differences were considered to be significant at $P<0.05$.

\section{RESULTS}

\section{Deletion of $\mathrm{AT}_{2} \mathrm{R}$ Accelerates Differentiation of Murine MSCs into Adipocytes}

Murine MSCs were isolated from the bone marrow of male AT2RKO mice and wild-type male littermates, and then incubated in adipogenic medium for 7 days. The differentiated adipocytes exhibited lipid droplets in the cytoplasm by phase contrast microscopy (Figure 1a) and this was verified using the AdipoRed fluorescent dye for lipids (Cambrex, Walkersville, MD, USA) (Figure 1b). Quantitation of the AdipoRed staining (Figure 1c-e) revealed significantly greater lipid droplet accumulation in the differentiated adipocytes from the AT2RKO MSCs than in those from the littermate group $(261.6 \pm 49.6 \% ; n=12 ; P<0.05)$, suggesting an antiadipogenic effect of $\mathrm{AT}_{2} \mathrm{R}$ on murine MSCs.

\section{Deletion of $\mathrm{AT}_{2} \mathrm{R}$ Increases the Expression of Adipogenic Marker Genes}

We also examined the expression of adipogenic marker genes by quantitative RT-PCR. Murine MSCs from AT2RKO mice and wild-type littermates were incubated in adipogenic medium for 7 days, then subjected to total RNA extraction and analyzed by real-time RT-PCR for mRNA expression of PPAR-gamma, FAS, and adiponectin. Consistent with the analysis of lipid droplet accumulation, PPAR-gamma, FAS, and adiponectin were upregulated in the AT2RKO-derived cells compared with the littermate controls $(4.32 \pm 2.21$-, $4.64 \pm 0.87-$, and $10.08 \pm 1.08$-fold increases, respectively; $n=4 ; P<0.05$; Figure 2a-c).

\section{Deletion of $\mathrm{AT}_{2} \mathrm{R}$ Prolongs the Acceleration of Adipogenesis}

We further examined the effect of deleting $\mathrm{AT}_{2} \mathrm{R}$ on adipogenesis over a prolonged period. Murine MSCs from AT2RKO mice and wild-type littermates were incubated in adipogenic medium for 14 days and then stained using Oil Red O to quantify the lipid droplet accumulation. Oil Red O staining, followed by extraction of the absorbed dye and measurement of the absorbance on day 14, exhibited that the AT2RKO group showed significantly increased lipid droplet accumulation (202.7 $\pm 14.1 \%$ vs littermate), confirming the anti-adipogenic effect of $\mathrm{AT}_{2} \mathrm{R}$ on murine MSCs (Figure $3 \mathrm{a}-\mathrm{c}$ ).

\section{Deletion of $\mathrm{AT}_{2} \mathrm{R}$ Decreases Wnt10b Expression}

As Wnt10b/beta-catenin signaling is reported to inhibit adipogenesis, we examined the expression of Wnt10b by quantitative RT-PCR. Murine MSCs from AT2RKO mice and wild-type littermates were incubated in adipogenic medium for 7 days, and then analyzed for the mRNA expression of Wnt10b. As shown in Figure 4, the AT2RKO group showed a remarkably decreased expression of Wnt10b compared with the littermate group $(0.0041 \pm 0.0015$-fold changes $v s$ the littermate group, respectively; $n=4 ; P<0.05)$.

\section{Deletion of $\mathrm{AT}_{2} \mathrm{R}$ Decreases Cellular Beta-Catenin}

To confirm the suppression of Wnt10b/beta-catenin signaling in the AT2RKO group, we further analyzed cellular betacatenin protein expression by immunoblotting. Murine MSCs from AT2RKO mice and wild-type littermates were incubated in adipogenic medium for 14 days. Cell lysates were then isolated and subjected to immunoblotting analysis using antibodies for beta-catenin, PPAR-gamma, and GAPDH. Cellular beta-catenin protein expression was decreased in the AT2RKO group compared with the littermate group (Figure $5 \mathrm{a}-\mathrm{c}$ ), and densitometric quantification from three independent experiments revealed that this decrease in beta-catenin expression to be significant (Figure 5d). Consistent with the results of mRNA expression, PPAR-gamma protein expression was increased in the AT2RKO cells compared with those from littermates (Figure 5e). These results suggest that the 

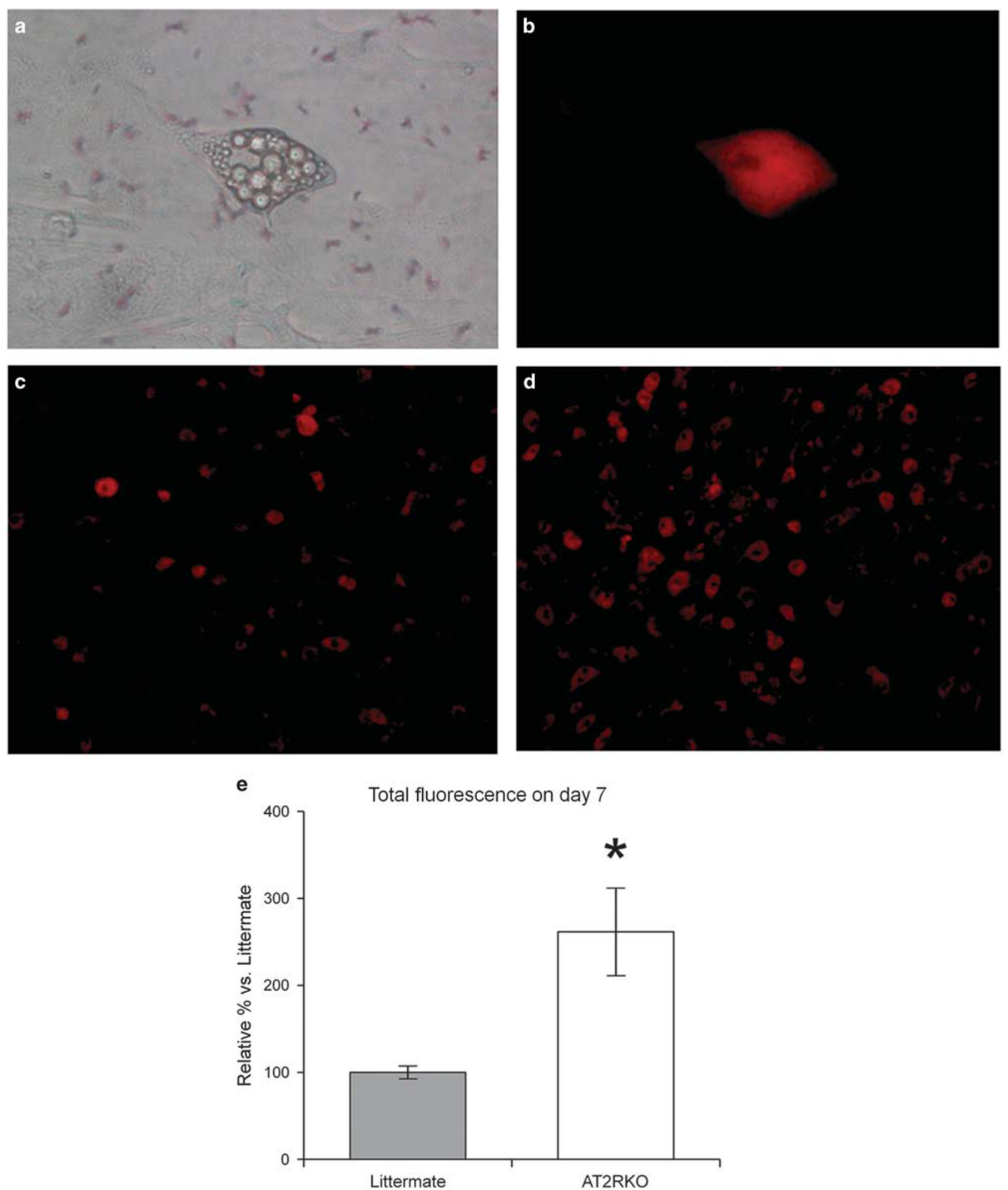

Figure 1 Deletion of $\mathrm{AT}_{2} \mathrm{R}$ accelerates adipocyte differentiation of murine MSCs. (a, b) Representative micrographs of differentiated adipocytes (day 7) from wild-type littermate MSCs (a: phase contrast, b: AdipoRed fluorescence; original magnification, $\times 400$ ) are shown. (c, d) Representative AdipoRed fluorescence micrographs of differentiated adipocytes (day 7) from wild-type littermate MSCs (c) and $A_{2}{ }_{2} R$-null (AT2RKO) MSCs (d) are shown. Original magnification, $\times 200$. (e) Quantification of fluorescent lipid droplet accumulation. Relative $\%$ vs Littermate group. Data are mean \pm s.d. $(n=12)$. ${ }^{*} P<0.05$ vs Littermate group. 

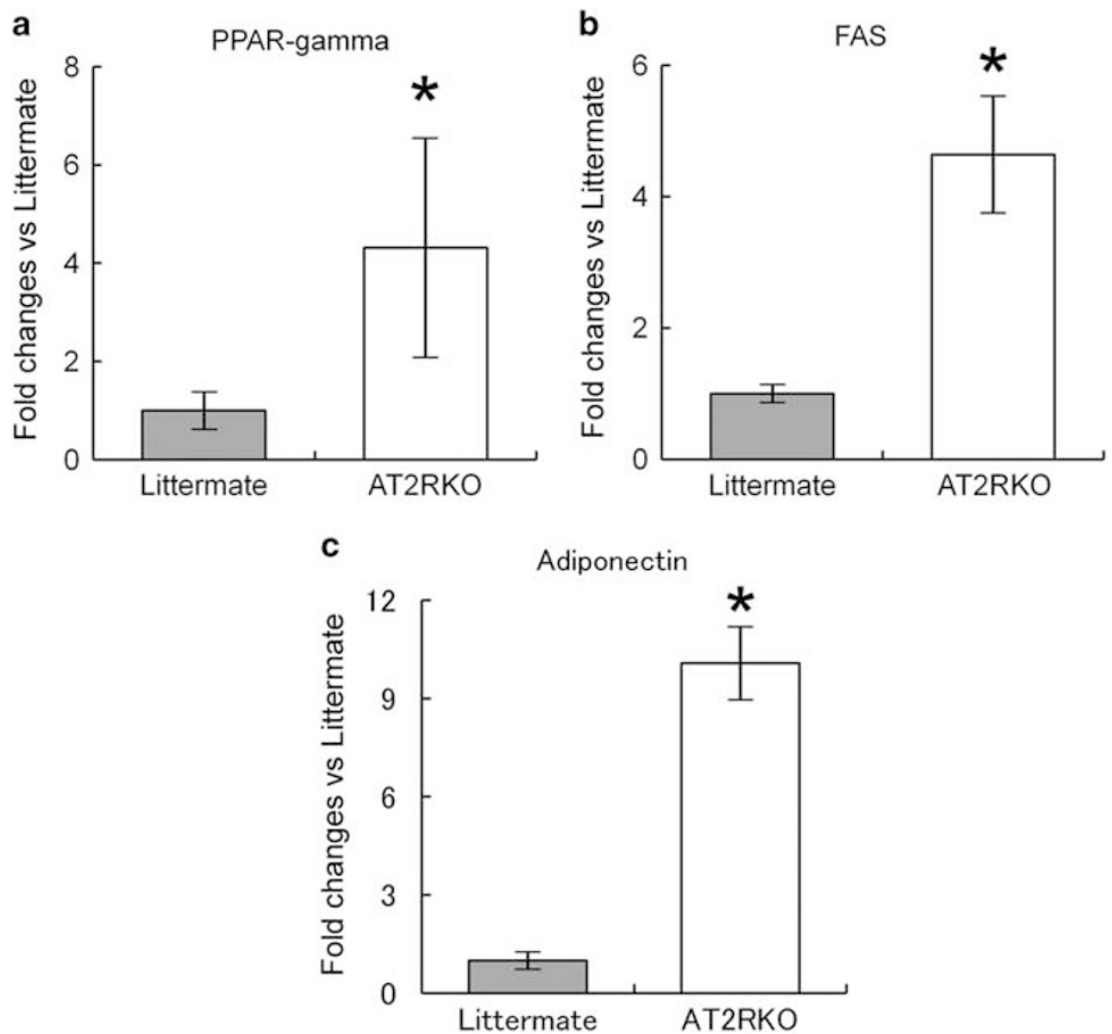

Figure 2 Expression of adipogenic marker genes. Murine MSCs from wild-type littermate (Littermate) and $A T_{2} R$-null (AT2RKO) mice were incubated in adipogenic medium for 7 days. Total RNA was analyzed by quantitative RT-PCR for mRNA expression of PPAR-gamma (a), fatty acid synthase (FAS) (b), and adiponectin (c) on day 7. Fold changes vs Littermate group. Data are mean \pm s.d. $(n=4) .{ }^{*} P<0.05$ vs Littermate group.

inhibitory effect of $\mathrm{AT}_{2} \mathrm{R}$ on the adipogenesis of murine MSCs is associated with $\mathrm{Wnt10b/beta-catenin} \mathrm{signaling.}$

\section{DISCUSSION}

This study demonstrates that the deletion of $\mathrm{AT}_{2} \mathrm{R}$ accelerates adipogenesis of MSCs, suggesting that $\mathrm{AT}_{2} \mathrm{R}$ has an inhibitory effect on adipogenesis. Furthermore, the inhibitory effect of $\mathrm{AT}_{2} \mathrm{R}$ on adipogenesis was associated experimentally with Wnt10b/beta-catenin signaling, which has a vital role in inhibiting adipocyte differentiation. Indeed, our data suggest that the increase in $\mathrm{AT}_{2} \mathrm{R}$ mRNA levels during adipogenesis ${ }^{27}$ contributes to the modulation of adipogenesis and obesity.

Obesity predisposes individuals to both type 2 diabetes and metabolic syndrome. Severe obesity is associated with an increase in adipocyte size combined with increased adipocyte number. ${ }^{4-6}$ New adipocytes arise from a pre-existing pool of adipose stem cells regardless of age, ${ }^{7-9}$ and recent studies likened adipose stem cells to bone marrow stromal MSCs. ${ }^{9-11}$ In addition to resident stem cells, Crossno et al. ${ }^{49}$ reported that adipocyte progenitor cells originating from bone marrow also contribute to development of new adipocytes in adult animals. Taken together, MSCs are suggested to have an important role in the maintenance of the mass and function of adult adipose tissue. Thus, the in vitro differentiation of MSCs toward the adipogenic lineage is the major research target for studying the regulation of adipogenesis and obesity. ${ }^{27,50}$

The RAS is central to the regulation of cardiovascular homeostasis. ${ }^{16-18}$ Previously, we reported that human MSCs contain a local RAS and produce endogenous angiotensin II. ${ }^{27}$ We also showed that $\mathrm{AT}_{2} \mathrm{R}$ mRNA is increased during adipogenesis of human MSC. ${ }^{27}$ Using a genetic model in the present study, we further built on our previous findings on the role of $\mathrm{AT}_{2} \mathrm{R}$ in adipogenesis ${ }^{27}$ to show that deletion of $\mathrm{AT}_{2} \mathrm{R}$ accelerates adipogenesis of murine MSCs. Together, these studies strongly indicate that $\mathrm{AT}_{2} \mathrm{R}$ could regulate adipogenesis in MSCs and, potentially, modulate obesity.

In general, failure to produce new adipocytes is considered to result in the increase in large insulin-resistant adipocytes and the predisposition to developing diabetes and metabolic syndrome. ${ }^{51}$ Thus, promoting the production of small, insulin-sensitive adipocytes is thought to yield medical benefits. Yvan-Charvet et al. ${ }^{52}$ reported that AT2RKO mice fed a low-fat diet had an increased number of small adipocyte cells as compared with wild-type mice. On the basis of our results, we speculate that such small adipocytes might be recruited from MSCs.

As obesity is considered as the main culprit of metabolic syndrome, studies into obesity control are of note. For example, based on the theory that obesity can be prevented 

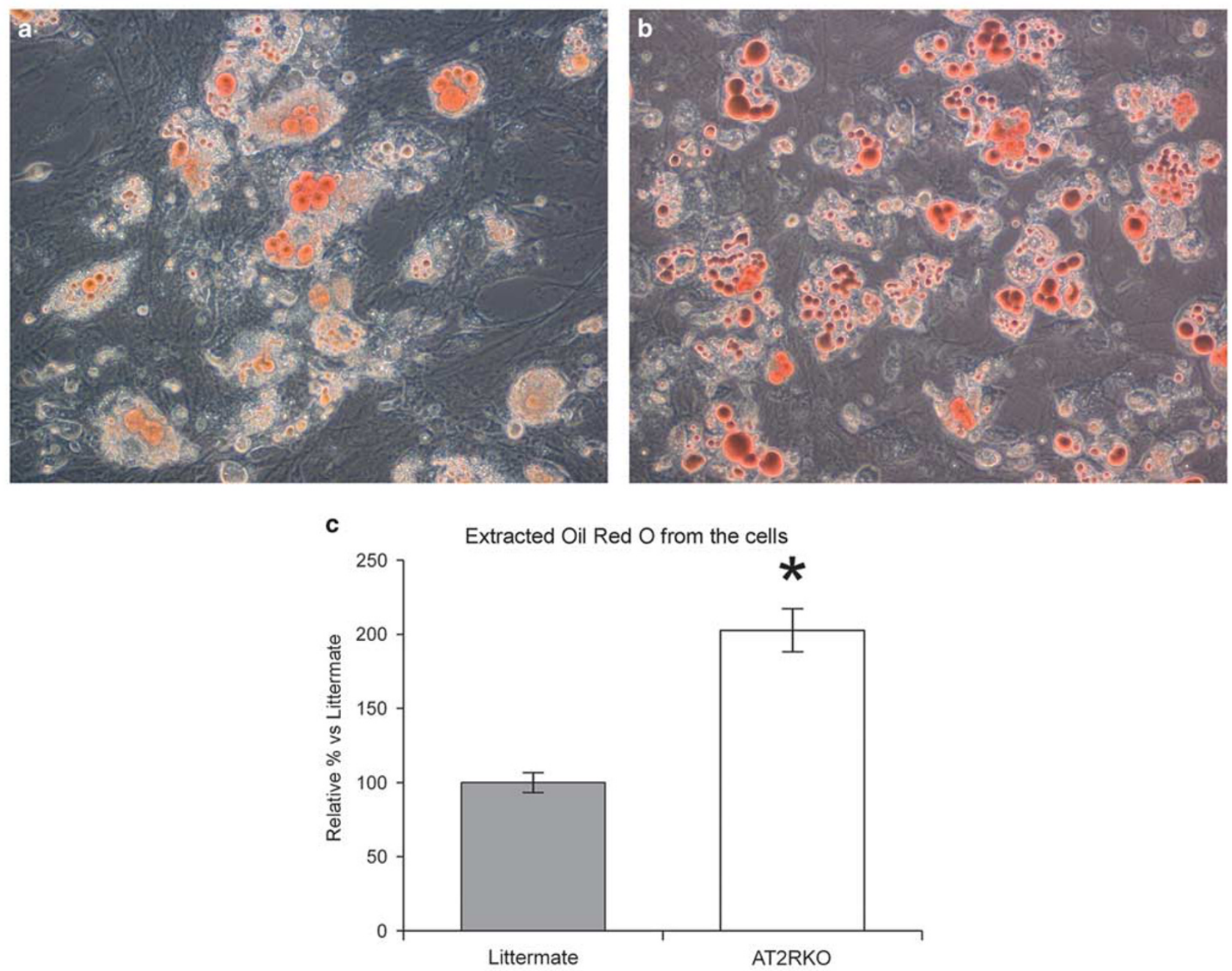

Figure 3 Deletion of $\mathrm{AT}_{2} \mathrm{R}$ prolongs acceleration of adipogenesis. (a, b) Representative micrographs of Oil red $\mathrm{O}$ staining of differentiated adipocytes (day 14) from wild-type littermate MSCs (a) and $A_{2} R$-null (AT2RKO) MSCs (b) are shown. Original magnification, $\times 200$. (c) Quantification of extracted Oil red $O$ from the cells. Relative \% vs Littermate group. Data are mean \pm s.d. $(n=4) .{ }^{*} P<0.05$ vs Littermate group.

through exercise, Rubin et al. ${ }^{53}$ showed that 15 weeks of brief, daily exposure to high-frequency mechanical signals, induced at a magnitude well below that encountered during walking, inhibited adipogenesis in mice. These authors further demonstrated that irradiated mice receiving bone marrow transplants from heterozygous green fluorescent protein+ mice showed a reduced commitment of MSC differentiation into adipocytes following 6 weeks of these low-magnitude mechanical signals, suggesting that such signals would suppress adiposity by suppressing the differentiation of MSCs into adipocytes, rather than by metabolizing existing adipose tissue. ${ }^{53}$ In the clinical setting, the most effective treatment for severe obesity is bariatric surgery. ${ }^{5-57}$ Importantly, such surgery to treat obesity was also reported to resolve hypertension, diabetes, and dyslipidemia, resulting in an overall reduction in cardiovascular risk. ${ }^{54-57}$ To investigate the mechanisms of this surgical treatment of obesity, Chen et al. $^{58}$ examined RAS-related gene expressions in human adipose-derived MSCs and differentiated adipocytes from three groups: non-obese control subjects, obese subjects undergoing bariatric surgery, and subjects 1 year or more after bariatric surgery. These authors demonstrated upregulation of the RAS-related gene expressions in MSCs and differentiated adipocytes of obese individuals and that such upregulation resolved in post-bariatric surgery subjects. ${ }^{58}$ These data together suggest that the treatment of obesity could ameliorate metabolic syndrome, possibly via the modulation of MSC adipogenesis. However, simple inhibition of adipogenesis alone is an inappropriate approach to manage obesity and metabolic syndrome, and obesity derived from an imbalance between energy intake and output must also be considered. ${ }^{59}$ Simply inhibiting the requisite adipogenesis 
would require an alternative site for the excess calories, and ectopic fat deposition is associated with insulin resistance, type 2 diabetes, and adverse metabolic phenotypes. ${ }^{60-64}$ An appropriate balance between promoting requisite adipogenesis and inhibiting excess adipogenesis seems to be important in maintaining a caloric equilibrium. Thus, although the roles of MSC adipogenesis in obesity and metabolic syndrome hold a significant promise for new treatment strategies, further studies are needed to support successful clinical applications of controlling MSC adipogenesis.

We also studied the mechanism by which $\mathrm{AT}_{2} \mathrm{R}$ could inhibit adipogenesis of murine MSCs. Wnt/beta-catenin

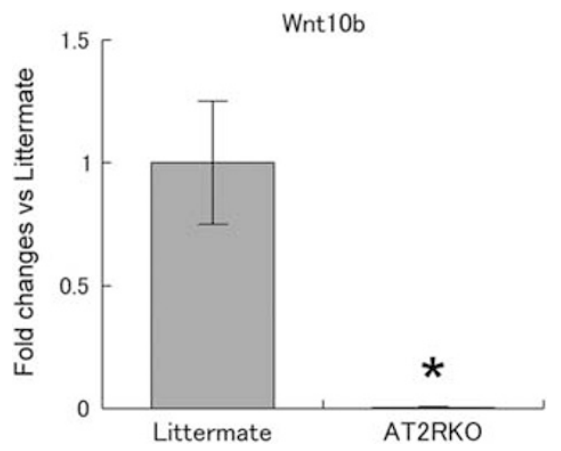

Figure 4 Deletion of $\mathrm{AT}_{2} \mathrm{R}$ remarkably decreases Wnt10b expression. Murine MSCs from wild-type littermate (Littermate) and $\mathrm{AT}_{2} \mathrm{R}$-null (AT2RKO) mice were incubated in adipogenic medium for 7 days. Total RNA was analyzed by quantitative RT-PCR for mRNA expression of Wnt10b on day 7. Fold changes vs Littermate group. Data are mean \pm s.d. $(n=4)$. ${ }^{*} P<0.05$ vs Littermate group. signaling is an important regulator of MSC fate $\mathrm{e}^{32,33}$ and also has a vital role in the adipogenic differentiation of preadipocytes. ${ }^{34,65}$ In particular, Wnt10b is the most important endogenous regulator of adipogenesis. ${ }^{34,66} \mathrm{Wnt} 10 \mathrm{~b}$ is considered to act as a brake on adipogenic differentiation by activating the canonical Wnt signaling pathway that leads to stabilization of cytosolic beta-catenin, ${ }^{34}$ and myoblasts from Wnt10b-null mice showed accelerated adipogenic potential. ${ }^{67}$ In addition, Longo et al. ${ }^{35}$ created transgenic mice overexpressing Wnt10b from the adipocyte-specific FABP4 promotor (FABP4-Wnt10b mice) that showed reduced adiposity and were resistant to diet-induced obesity, while Wright et al. ${ }^{36}$ reported that expression of Wnt10b in adipose tissue reduces adiposity in the $o b / o b$ obesity model and that Wnt10b protected against genetic obesity in mice due to ectopic expression of agouti $\left(\mathrm{A}^{y}\right)$. In the present study, deletion of $\mathrm{AT}_{2} \mathrm{R}$ significantly decreased Wnt10b and betacatenin expression, confirming that Wnt10b/beta-catenin signaling is suppressed in the $\mathrm{AT}_{2} \mathrm{R}$-null cells. These findings suggest that the inhibitory effect of $\mathrm{AT}_{2} \mathrm{R}$ on MSC adipogenesis is associated with Wnt10b/beta-catenin signaling; however, it should be noted that this may not be causal and may instead reflect Wnt-dependent and/or Wnt-independent changes. In addition, although Wnt10b/beta-catenin signaling has been suggested as one of the most important pathways, there are a number of molecules that regulate adipogenesis. Therefore, further studies are needed into the anti-adipogenic effect of $\mathrm{AT}_{2} \mathrm{R}$, particularly in light of the potential therapeutic applications of such findings.

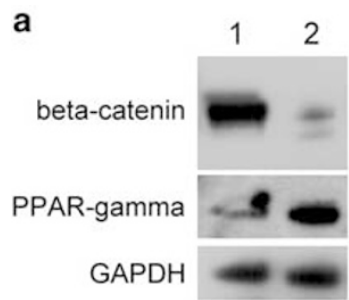

b

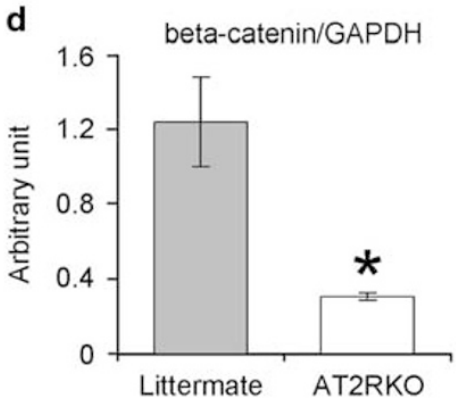

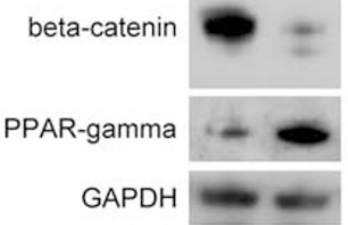

C
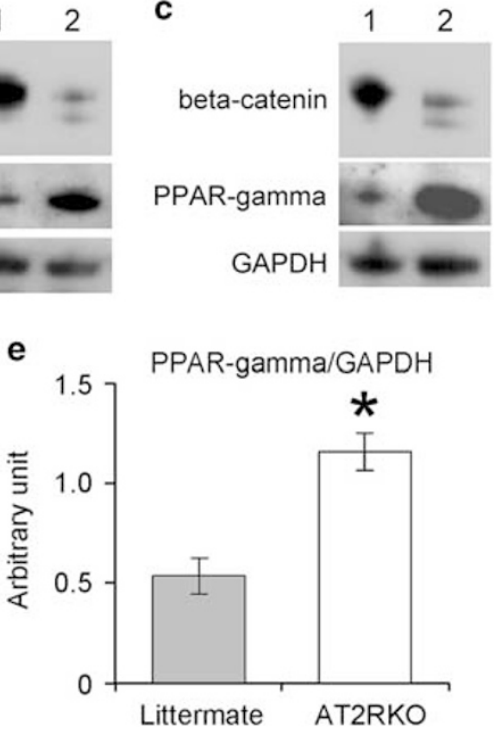

Figure 5 Deletion of $A T_{2} R$ decreases cellular beta-catenin. Murine MSCs from wild-type littermate (Littermate) and $A T_{2} R$-null (AT2RKO) mice were incubated in adipogenic medium for 14 days. Cell lysates were isolated and subjected to immunoblotting analysis using antibodies for beta-catenin, PPAR-gamma, and GAPDH. (a-c) The blots from three independent experiments are shown. Lane 1, Littermate; Lane 2, AT2RKO. (d, e) Densitometric quantitation for beta-catenin/GAPDH (d) and PPAR-gamma/GAPDH (e) from three independent experiments. Data are mean \pm s.e.m.; ${ }^{*} P<0.05$ vs Littermate group. 
In conclusion, the present study demonstrates that $\mathrm{AT}_{2} \mathrm{R}$ inhibits adipocyte differentiation of murine MSCs with Wnt10b/beta-catenin signaling, which might be physiologically important in maintaining the mass and function of adult adipose tissue. Our results thus support a key role for $\mathrm{AT}_{2} \mathrm{R}$ in adipose tissue that could be important in future research of obesity. Further characterization of this $\mathrm{AT}_{2} \mathrm{R}$ function in adipocyte biology could potentially reveal therapeutic implications for obesity and obesity-related consequences, such as metabolic syndrome.

\section{ACKNOWLEDGMENTS}

We thank Hui Mu for her technical assistance. This work was supported, in whole or in part, by grants from the National Heart, Lung, and Blood Institute (RO1 HL35610, HL58516, HL72010, and HL73219 to VJD), the Edna Mandel Foundation (to VJD), the Leducq Foundation (to VJD), the Ministry of Education, Culture, Sports, Science, and Technology of Japan (KAKENHI 21790745 to KM), the Japan Society for the Promotion of Science (KAKENHI 26461086 to KM), and the Uehara Memorial Foundation (to KM).

\section{DISCLOSURE/CONFLICT OF INTEREST}

The authors declare no conflict of interest.

1. Grundy SM, Cleeman Jl, Daniels SR, et al. Diagnosis and management of the metabolic syndrome: an American Heart Association/National Heart, Lung, and Blood Institute Scientific Statement. Circulation 2005;112:2735-2752.

2. Hajer GR, van Haeften TW, Visseren FL. Adipose tissue dysfunction in obesity, diabetes, and vascular diseases. Eur Heart J 2008;29: 2959-2971.

3. Mottillo S, Filion KB, Genest J, et al. The metabolic syndrome and cardiovascular risk a systematic review and meta-analysis. J Am Coll Cardiol 2010:56:1113-1132.

4. Brook CG, Lloyd JK, Wolf OH. Relation between age of onset of obesity and size and number of adipose cells. Br Med J 1972;2:25-27.

5. Faust IM, Johnson PR, Stern JS, et al. Diet-induced adipocyte number increase in adult rats: a new model of obesity. Am J Physiol 1978;235: E279-E286.

6. Hirsch J, Batchelor B. Adipose tissue cellularity in human obesity. Clin Endocrinol Metab 1976;5:299-311.

7. Otto TC, Lane MD. Adipose development: from stem cell to adipocyte. Crit Rev Biochem Mol Biol 2005:40:229-242.

8. Phillips BW, Vernochet C, Dani C. Differentiation of embryonic stem cells for pharmacological studies on adipose cells. Pharmacol Res 2003;47:263-268

9. Zuk PA, Zhu M, Mizuno $\mathrm{H}$, et al. Multilineage cells from human adipose tissue: implications for cell-based therapies. Tissue Eng 2001;7: 211-228.

10. De Ugarte DA, Morizono K, Elbarbary et al. Comparison of multilineage cells from human adipose tissue and bone marrow. Cells Tissues Organs 2003;174:101-109.

11. Lee RH, Kim B, Choi I, et al. Characterization and expression analysis of mesenchymal stem cells from human bone marrow and adipose tissue. Cell Physiol Biochem 2004;14:311-324.

12. Liechty KW, MacKenzie TC, Shaaban AF, et al. Human mesenchymal stem cells engraft and demonstrate site-specific differentiation after in utero transplantation in sheep. Nat Med 2000;6:1282-1286.

13. Bost $F$, Aouadi $M$, Caron $L$, et al. The role of MAPKs in adipocyte differentiation and obesity. Biochimie 2005;87:51-56.

14. Hausman DB, DiGirolamo M, Bartness TJ, et al. The biology of white adipocyte proliferation. Obes Rev 2001;2:239-254.

15. Scavo LM, Karas M, Murray $M$, et al. Insulin-like growth factor-I stimulates both cell growth and lipogenesis during differentiation of human mesenchymal stem cells into adipocytes. J Clin Endocrinol Metab 2004;89:3543-3553.

16. Dzau V. The cardiovascular continuum and renin-angiotensinaldosterone system blockade. J Hypertens Suppl 2005;23:S9-S17.
17. Dzau VJ. Circulating versus local renin-angiotensin system in cardiovascular homeostasis. Circulation 1988;77(6 Pt 2):14-13.

18. Dzau VJ, Hirsch AT. Emerging role of the tissue renin-angiotensin systems in congestive heart failure. Eur Heart J 1990;11(Suppl B):65-71.

19. de Kloet AD, Krause EG, Woods SC. The renin angiotensin system and the metabolic syndrome. Physiol Behav 2010;100:525-534.

20. Prasad A, Quyyumi AA. Renin-angiotensin system and angiotensin receptor blockers in the metabolic syndrome. Circulation 2004;110: 1507-1512.

21. Putnam K, Shoemaker R, Yiannikouris $F$, et al. The renin-angiotensin system: a target of and contributor to dyslipidemias, altered glucose homeostasis, and hypertension of the metabolic syndrome. Am J Physiol Heart Circ Physiol 2012;302:H1219-H1230.

22. Darimont C, Vassaux G, Ailhaud G, et al. Differentiation of preadipose cells: paracrine role of prostacyclin upon stimulation of adipose cells by angiotensin-II. Endocrinology 1994;135:2030-2036.

23. Janke J, Engeli S, Gorzelniak K, et al. Mature adipocytes inhibit in vitro differentiation of human preadipocytes via angiotensin type 1 receptors. Diabetes 2002:51:1699-1707.

24. Palominos MM, Dunner $\mathrm{NH}$, Wabitsch $\mathrm{M}$, et al. Angiotensin II directly impairs adipogenic differentiation of human preadipose cells. Mol Cell Biochem 2015;408:115-122.

25. Schling P. Expression of angiotensin II receptors type 1 and type 2 in human preadipose cells during differentiation. Horm Metab Res 2002;34:709-715.

26. Schling P, Loffler G. Effects of angiotensin II on adipose conversion and expression of genes of the renin-angiotensin system in human preadipocytes. Horm Metab Res 2001;33:189-195.

27. Matsushita $\mathrm{K}, \mathrm{Wu} \mathrm{Y}$, Okamoto $\mathrm{Y}$, et al. Local renin angiotensin expression regulates human mesenchymal stem cell differentiation to adipocytes. Hypertension 2006;48:1095-1102.

28. Muruganandan S, Roman AA, Sinal CJ. Adipocyte differentiation of bone marrow-derived mesenchymal stem cells: cross talk with the osteoblastogenic program. Cell Mol Life Sci 2009;66:236-253.

29. Nuttall ME, Gimble JM. Controlling the balance between osteoblastogenesis and adipogenesis and the consequent therapeutic implications. Curr Opin Pharmacol 2004;4:290-294.

30. Takada I, Kouzmenko AP, Kato S. Molecular switching of osteoblastogenesis versus adipogenesis: implications for targeted therapies. Expert Opin Ther Targets 2009;13:593-603.

31. Matsushita $\mathrm{K}, \mathrm{Wu} \mathrm{Y}$, Pratt RE, et al. Blockade of angiotensin II type 2 receptor by PD123319 inhibits osteogenic differentiation of human mesenchymal stem cells via inhibition of extracellular signal-regulated kinase signaling. J Am Soc Hypertens 2015;9:517-525.

32. Davis LA, Zur Nieden NI. Mesodermal fate decisions of a stem cell: the Wnt switch. Cell Mol Life Sci 2008;65:2658-2674.

33. Satija NK, Gurudutta GU, Sharma S, et al. Mesenchymal stem cells: molecular targets for tissue engineering. Stem Cells Dev 2007;16:7-23.

34. Ross SE, Hemati N, Longo KA, et al. Inhibition of adipogenesis by Wnt signaling. Science 2000;289:950-953.

35. Longo KA, Wright WS, Kang $S$, et al. Wnt10b inhibits development of white and brown adipose tissues. J Biol Chem 2004;279:35503-35509.

36. Wright WS, Longo KA, Dolinsky VW, et al. Wnt10b inhibits obesity in ob/ob and agouti mice. Diabetes 2007:56:295-303.

37. Akishita $M$, Ito $M$, Lehtonen JY, et al. Expression of the AT2 receptor developmentally programs extracellular signal-regulated kinase activity and influences fetal vascular growth. J Clin Invest 1999:103:63-71.

38. Akishita $M$, Iwai $M, W u L$, et al. Inhibitory effect of angiotensin II type 2 receptor on coronary arterial remodeling after aortic banding in mice. Circulation 2000;102:1684-1689.

39. Hein L, Barsh GS, Pratt RE, et al. Behavioural and cardiovascular effects of disrupting the angiotensin II type-2 receptor in mice. Nature 1995;377:744-747.

40. Bruder SP, Jaiswal N, Haynesworth SE. Growth kinetics, self-renewal, and the osteogenic potential of purified human mesenchymal stem cells during extensive subcultivation and following cryopreservation. J Cell Biochem 1997;64:278-294.

41. Colter DC, Class R, DiGirolamo CM, et al. Rapid expansion of recycling stem cells in cultures of plastic-adherent cells from human bone marrow. Proc Natl Acad Sci USA 2000;97:3213-3218.

42. Ip JE, Wu Y, Huang J, et al. Mesenchymal stem cells use integrin beta1 not CXC chemokine receptor 4 for myocardial migration and engraftment. Mol Biol Cell 2007;18:2873-2882. 
43. Mangi AA, Noiseux N, Kong D, et al. Mesenchymal stem cells modified with Akt prevent remodeling and restore performance of infarcted hearts. Nat Med 2003;9:1195-1201.

44. Matsushita K, Morello F, Wu Y, et al. Mesenchymal stem cells differentiate into renin-producing juxtaglomerular (JG)-like cells under the control of liver X receptor-alpha. J Biol Chem 2010;285:11974-11982.

45. Mirotsou M, Zhang Z, Deb et al. Secreted frizzled related protein 2 (Sfrp2) is the key Akt-mesenchymal stem cell-released paracrine factor mediating myocardial survival and repair. Proc Natl Acad Sci USA 2007; 104:1643-1648.

46. Pereira RF, Halford KW, O'Hara MD, et al. Cultured adherent cells from marrow can serve as long-lasting precursor cells for bone, cartilage, and lung in irradiated mice. Proc Natl Acad Sci USA 1995;92: 4857-4861.

47. Prockop DJ. Marrow stromal cells as stem cells for nonhematopoietic tissues. Science 1997;276:71-74.

48. Livak KJ, Schmittgen TD. Analysis of relative gene expression data using real-time quantitative PCR and the 2(-Delta Delta C(T)) Method. Methods 2001:25:402-408.

49. Crossno JT Jr, Majka SM, Grazia T, et al. Rosiglitazone promotes development of a novel adipocyte population from bone marrowderived circulating progenitor cells. J Clin Invest 2006;116:3220-3228.

50. Mogi M, Iwai M, Horiuchi M. Emerging concept of adipogenesis regulation by the renin-angiotensin system. Hypertension 2006;48: 1020-1022.

51. Okuno $\mathrm{A}$, Tamemoto $\mathrm{H}$, Tobe $\mathrm{K}$, et al. Troglitazone increases the number of small adipocytes without the change of white adipose tissue mass in obese Zucker rats. J Clin Invest 1998;101:1354-1361.

52. Yvan-Charvet $L$, Even $P$, Bloch-Faure $M$, et al. Deletion of the angiotensin type 2 receptor (AT2R) reduces adipose cell size and protects from diet-induced obesity and insulin resistance. Diabetes 2005;54:991-999.

53. Rubin CT, Capilla E, Luu YK, et al. Adipogenesis is inhibited by brief, daily exposure to high-frequency, extremely low-magnitude mechanical signals. Proc Natl Acad Sci USA 2007;104:17879-17884.
54. Batsis JA, Sarr MG, Collazo-Clavell ML, et al. Cardiovascular risk after bariatric surgery for obesity. Am J Cardiol 2008;102:930-937.

55. Heneghan HM, Meron-Eldar S, Brethauer SA, et al. Effect of bariatric surgery on cardiovascular risk profile. Am J Cardiol 2011;108: 1499-1507.

56. Sjostrom $\mathrm{L}$, Lindroos $\mathrm{AK}$, Peltonen $\mathrm{M}$, et al. Lifestyle, diabetes, and cardiovascular risk factors 10 years after bariatric surgery. $\mathrm{N}$ Engl J Med 2004;351:2683-2693.

57. Torquati A, Wright K, Melvin W, et al. Effect of gastric bypass operation on Framingham and actual risk of cardiovascular events in class II to III obesity. J Am Coll Surg 2007;204:776-782 discussion 782-773.

58. Chen JG, Spagnoli A, Torquati A. Adipogenic differentiation of adipose tissue-derived human mesenchymal stem cells: effect of gastric bypass surgery. Surg Endosc 2012;26:3449-3456.

59. Rosen ED, Walkey $C J$, Puigserver $P$, et al. Transcriptional regulation of adipogenesis. Genes Dev 2000;14:1293-1307.

60. Cusi K. The role of adipose tissue and lipotoxicity in the pathogenesis of type 2 diabetes. Curr Diab Rep 2010;10:306-315

61. Hocking $\mathrm{S}$, Samocha-Bonet $\mathrm{D}$, Milner $\mathrm{KL}$, et al. Adiposity and insulin resistance in humans: the role of the different tissue and cellular lipid depots. Endocr Rev 2013;34:463-500.

62. Lim S. Ectopic fat assessment focusing on cardiometabolic and renal risk. Endocrinol Metab (Seoul, Korea) 2014;29:1-4.

63. Ma X, Lee $\mathrm{P}$, Chisholm DJ, et al. Control of adipocyte differentiation in different fat depots; implications for pathophysiology or therapy. Front Endocrinol (Lausanne) 2015;6:1.

64. Sattar N, Gill JM. Type 2 diabetes as a disease of ectopic fat? BMC Med 2014;12:123.

65. Bennett CN, Ross SE, Longo KA, et al. Regulation of Wnt signaling during adipogenesis. J Biol Chem 2002;277:30998-31004.

66. Wend $\mathrm{P}$, Wend $\mathrm{K}$, Krum SA, et al. The role of WNT10B in physiology and disease. Acta Physiol (Oxford, England) 2012;204:34-51.

67. Vertino AM, Taylor-Jones JM, Longo KA, et al. Wnt10b deficiency promotes coexpression of myogenic and adipogenic programs in myoblasts. Mol Biol Cell 2005;16:2039-2048. 